\title{
A critical hermeneutic reflection on the paradigm-level assumptions underlying responsible innovation
}

\author{
Job Timmermans ${ }^{1}$ - Vincent Blok $^{1}$
}

Received: 15 January 2018 / Accepted: 31 May 2018 / Published online: 9 June 2018

(C) The Author(s) 2018

\begin{abstract}
The current challenges of implementing responsible innovation (RI) can in part be traced back to the (implicit) assumptions behind the ways of thinking that ground the different pre-existing theories and approaches that are shared under the RI-umbrella. Achieving the ideals of RI, therefore not only requires a shift on an operational and systemic level but also at the paradigm-level. In order to develop a deeper understanding of this paradigm shift, this paper analyses the paradigm-level assumptions that are (implicitly) being brought forward by the different conceptualizations of RI. To this purpose it deploys (1) a pragmatic stance on paradigms that allows discerning ontological and axiological elements shared by the RI community and (2) an accompanying critical hermeneutic research approach that enables the profiling of paradigmatic beliefs and assumptions of accounts of RI. The research surfaces the distance of four salient RI accounts from the currently dominant techno-economic innovation paradigm RI seeks to shift. With this, our contribution helps to raise the self-awareness of the RI community about their presuppositions and the paradigm level barriers and enablers to reaching the RI ideal. This insight is needed for a successful transition to responsible research and innovation practices.
\end{abstract}

Keywords Responsible innovation - Critical hermeneutics · Paradigm level assumptions

$凶$ Job Timmermans

jfc.timmermans@mindef.nl

1 Social Sciences Group, Wageningen University, Wageningen, The Netherlands 


\section{Introduction}

In the literature, responsible innovation (RI) is being portrayed as involving a transition in innovation practices such that their products and processes are aligned with social and ethical needs (Timmermans 2015a). Thus far, the issues and challenges accompanying this transition are predominantly addressed on a conceptual and practical level, ranging from governance frameworks (Owen et al. 2013) to hands-on tools to implement RI in practice (e.g. RRI Tools Project 2016). At the same time, an emerging strand in the literature highlights the tensions between the ideals of RI and innovation practice (e.g. Blok and Lemmens 2015). This raises the question whether the introduction of governance frameworks and tools is sufficient to achieve RI's societal ambitions.

In the adjacent field of sustainability transition-literature, it is being argued that to adequately tackle the global sustainability challenges humanity is facing, the required changes have to be understood on a more fundamental level, i.e. beyond the operational or systemic level (Geels 2002, 2005). Likewise, we maintain that the tensions between the ideals of RI and innovation practice can be traced back to the (implicit) assumptions that ground the different pre-existing theories and approaches that are shared under the RI-umbrella. These assumptions may be mal-adjusted or even in tension with those held by the dominant techno-economic paradigm of innovation, which is still prevalent in the current innovation practice. On the one hand, for example, by incorporating the notion of 'innovation', RI is firmly rooted in the classic economic paradigm (see e.g. Blok and Lemmens 2015; van den Hoven 2013; Zwart et al. 2014). On the other hand, by explicitly building on the Ethical Legal and social implications or aspects (ELSI/ELSA), Science and Technology Studies (STS) and Constructive Technology Assessment (CTA) traditions (see, e.g., Fisher and Rip 2013; Grunwald 2011; Stilgoe et al. 2013), RI is assumed to be understood and established within a social governanceparadigm. Making societal actors such as the general public and NGOs co-responsible for innovation processes, as is aspired by some accounts of RI (see, e.g., Stilgoe et al. 2013; Von Schomberg 2013), presupposes a fundamental change in the valuation of innovation; it requires a shift beyond the dominant view of innovation as a means to create economic value in order to become a source of societal value. These examples show that apart from a transition at the operational and systemic levels, a transition at the paradigm-level is needed to achieve the ideals of RI.

In order to develop a deeper understanding of the paradigm shift which is needed to achieve its societal aspirations, this paper analyses the paradigm-level assumptions that (implicitly) are being brought forward by the different conceptualizations of RI. The paper starts by defining paradigm for the purpose of analyzing the ontological and axiological paradigm level assumptions of RI. Second, building on this conception, a critical hermeneutic research approach is introduced that enables identifying, articulating and then analyzing the paradigm level assumptions of the four currently most influential accounts of RI. Third, the assumptions of the different conceptualizations of RI are discussed in contrast to each other and to the dominant techno-economic paradigm of innovation. This last step allows mapping the tensions and alignments that currently exist between the different accounts of RI and the dominant paradigm. Based on these insights recommendations are made on how to deal with the challenges 
and issues RI currently faces on a conceptual and practical level, which is needed for a successful transition to more responsible forms of innovation.

\section{A pragmatic view of paradigm}

The concept of paradigm was first introduced by Thomas Kuhn (1962). Over time it has been used and re-interpreted in different ways (Given 2008). Especially during the last quarter of the twentieth century, the concept was used by social scientists to bring forward new views on doing research qualitatively, often in areas that thus far were dominated by quantitative methods of doing social research (Burrell and Morgan 1979; Given 2008; Guba and Lincoln 1994; Morgan 2007). Besides in science, the concept also has been used in other domains, such as sustainability (Burns 2012; Stead and Garner Stead 1994; Zagonari 2016), policy-analysis (Burns et al. 2009), management theory (Gladwin et al. 1995) and innovation (Baldwin and von Hippel 2009; Howaldt et al. 2016; Sundbo 1995).

To meet our current purpose of analyzing RI on a paradigm level, we use a pragmatic understanding of paradigm (see, e.g., Ritchie and Lewis 2003; Morgan 2007; Given 2008). Rather than emphasizing metaphysical issues related to the nature of reality and truth, this outlook accentuates the social aspect of paradigms. A paradigm then is defined as a set of assumptions and perceptual orientations, shared by members of a community (Denscombe 2008; Given 2008; Morgan 2007). It denotes a worldview held by a particular community, in a particular context and at a particular point in time (Ratcliffe 1983).

Paradigms are normative. They determine what is viewed by the community as "important and unimportant, reasonable and unreasonable, legitimate and illegitimate, possible and impossible, and what to attend to and what to ignore." (Ratcliffe 1983). Paradigms thus span a bounded performative space within which certain activities or actions are regarded as possible, reasonable, legitimate, and important while others are excluded as being impossible, illegitimate, unreasonable, and unimportant (Burns et al. 2009).

In daily practice, work by members of the community operating within this performative space results in further 'cementing and normalizing the operative paradigm' (Burns et al. 2009, p. 11). However, activities also may give rise to issues and problems that fail to be recognized, understood or addressed within the current paradigm. Efforts undertaken in dealing with these anomalies either may result in a reformulation of the existing paradigm, i.e. a mere shifting of the paradigm's boundaries to accommodate the anomalies, or more radically, to a complete replacement by a competing paradigm (Burns et al. 2009; Sundbo 1995).

Paradigm shifts or replacements not only rest on cognitive development, for example, based on insight shared in academic literature. They may also change due to choices and actions undertaken by the community members in their everyday practices. However, because RI predominantly is being introduced in a top-down manner (Burget et al. 2017), this research limits itself to the former, i.e. RI as an approach that addresses perceived anomalies in the dominant innovation paradigm as discussed in academic and policy documents. 
Furthermore, in both cases, the agents must have some basis of power or influence to (unconsciously and unintendedly) contribute to bringing about or to resist a paradigm shift (Burns et al. 2009; Surel 2000; Wall et al. 2015). For example, agents with a dominant position in a system, such as policymakers, can initiate paradigm changes by addressing existing policy failures or problems in new policies and regulations (Burns et al. 2009). In the domain of science, ideally, influence rests on the exchange of arguments within an ideal speech situation abstained from coercive power (Habermas 1984; Wall et al. 2015). Here exercising (soft-)power then involves convincing a paradigm-community by providing compelling arguments that support the (implicit) changes (Luoto et al. 2017). However, in science also conservative powers may be in play. For example, including new ideas in an article that challenge the dominant paradigm, may reduce the chances of having the article published (Alvesson and Sandberg 2011).

When the hinder caused by the anomalies within the dominant paradigm increases, the community also may become more receptive to paradigm-level changes, thereby generating a pull for shifts instead of a push. The introduction and adoption of a new paradigm are then based on the power of change agents to influence and change the paradigm, and on the openness to change of the paradigm-community members.

In order to understand how RI relates to the dominant innovation paradigm, this research analyses the paradigm level assumptions presupposed by RI relative to those of the dominant paradigm. In the literature, several types of paradigm level assumptions have been suggested for this type of analysis. A commonly used framework in social science methodology, for example, distinguishes between ontological, epistemological, methodological and axiological assumptions (Denzin and Lincoln 2005; Guba and Lincoln 1994; Morgan 2007). Ontology refers to basic assumptions about reality, epistemology entails the nature and origin of knowledge, methodology is the study of the epistemological assumptions implicit in specific methods, which includes the way of looking at a phenomenon, and axiology concerns that which is of value or worthwhile (Given 2008; Morgan 2007). For our current purposes, we limit ourselves to ontological and axiological assumptions. The reason is that ontological and axiological assumptions support the investigation of the perception, understanding and valuation of (social) reality in a practical domain such as innovation, while methodological and epistemological assumptions are more relevant in case a particular scientific discipline is involved (see, e.g., Fagerberg et al. 2013). So, although ontological and axiological changes involve epistemological and methodological changes as well, in this initial research we limit ourselves to the question how the world is perceived, rather than how that knowledge is procured.

This delimitation is also practiced in other efforts to analyze paradigms in particular practical domains. Burns and Carson's (2002) study of institutional paradigms, for instance, limits itself to cognitive assumptions, which focus on 'how the world works' (similar to ontological assumptions), and normative assumptions that focus on 'how things should be' (similar to axiological assumptions). Likewise, Gladwin et al.'s (1995) investigation of organizations makes a basic distinction between ontological and ethical (similar to axiological) assumptions.

In sum, in this research, a paradigm is defined as a set of assumptions and perceptual orientations, shared by members of a community. Together the ontology, i.e. the form 
and nature of reality, and axiology, i.e. that which is of value or worthwhile, span a bounded performative space. Paradigm shifts occur when the paradigm's boundaries to accommodate anomalies that arise are contested. Shifting paradigm boundaries involves an interplay between the conservative and progressive powers to influence the community.

\section{Critical hermeneutic research approach}

Paradigms are expressed and articulated through discourses and through social action and interaction (Alvesson and Sandberg 2011; Burns et al. 2009; Luoto et al. 2017). As discussed in the previous section, this research limits itself to the arguments that support the (implicit) changes to the reigning paradigm provided in publications. A research approach that allows investigating the ontological and axiological paradigm level assumptions in publications is Critical Hermeneutics. ${ }^{1}$ First developed by Ricoeur (1981), Ricoeur and Thompson (1981) and Habermas (1978, 1988, 1990), Critical Hermeneutics combines the hermeneutic and critical theory traditions allowing it to transcend previously taken for granted paradigms and look critically from the outside at their assumptions and practices (Given 2008). It is hermeneutical because it consists in the reconstruction of a deeper understanding and interpretation of a published source. It is critical because it thereby also analyses and disrupts the imposition (expression of social power) of preconceptions held as it is encountered. The approach thus offers a reflexive insight into the paradigm level assumptions of RI as means to shift or replace the dominant techno-economic innovation paradigm.

Part of the critical approach is to reflect on the position of the investigator relative to the phenomenon investigated. Both authors of this article have been engaged with RI for many years by publishing research papers and book chapters on the concept and application of RI. Also, they have been members of dedicated RI projects. The authors, however, have not forwarded an account of RI themselves nor have they committed themselves to one of the accounts discussed here in particular. Although this investigation is motivated and informed by their earlier engagement with RI, its purpose is not to promote or criticize a particular account of RI. Instead, the investigation is meant to generate a better self-understanding by the authors as members of the RI community about what they mean by RI, how this differs from the dominant techno-economic innovation paradigm, and why that difference makes a difference in terms of RI's overarching societal and ethical aspirations.

Our approach then consists of the following three iterative steps.

\subsection{Step 1: source selection}

In step 1, sources are singled out that are representative of the (implicit) paradigm-level assumptions underlying the RI discourse. To this end, contributions to the discourse

\footnotetext{
${ }^{1}$ Recently, hermeneutics also has been discussed in the literature on RI as an orientation to support the anticipatory dimension of RI (Grunwald 2014; Nordmann 2014; van der Burg 2014).
} 
Table 1 Four accounts of RI with the abbreviation used in this text and its source

\begin{tabular}{lll}
\hline Account & Abbreviation & Source \\
\hline European Commission & EC & Geoghegan-Quinn (2012) \\
Von Schomberg & VS & Von Schomberg (2013) \\
Stilgoe, Owen and Macnaghten & SOM & Stilgoe et al. (2013) \\
Van den Hoven & VDH & van den Hoven (2013) \\
\hline
\end{tabular}

via published papers, are selected from the body of RI literature that meet the following requirements:

1. They must put forward a comprehensive definition and/or framework of RI. This is to make sure that all relevant presuppositions underlying the particular view on RI can be captured.

2. They must put forward an original account of RI to keep the analysis focused and prevent unnecessary redundancies.

3. They must be the most influential contributions within the discourse such that only sources are included that are most likely to actually shift the paradigm (Cf. Alvesson and Sandberg 2011; Burns and Carson 2002).

Over the last years, several literature reviews of RI have been undertaken (Burget et al. 2017; Lubberink et al. 2017; Timmermans 2017; Wickson and Carew 2014). These were consulted to identify the different accounts of RI put forward by the RI discourse (first requirement). However, rather than constituting a new account by themselves, several of the accounts were compiled out of pre-existing accounts and, therefore, were considered to lack novelty (second requirement). For this reason, for example, the accounts by Sutcliffe (2011), the RRI tools project (Klaassen et al. 2014), and Wickson and Carew (2014) are left out. Lastly, the level of influence of an account (third requirement) was established by consulting an elaborate discourse analysis by Timmermans (2015b) that ranked publications and their authors based on cross-citation scores and their membership of RI projects. This way the less influential accounts, for example, those by Stahl et al. (2013) and Mason (2012) were left out as the analysis.

This way four salient accounts of RI were selected for further analysis, see Table 1.

The accounts by Stilgoe et al. and van den Hoven use the phrase 'Responsible Innovation' (RI) while the accounts by the European Commission and Von Schomberg use 'Responsible Research and Innovation' (RRI). In the literature, these two phrases are used next to each other, indicating the same phenomenon/concept. However, as will be discussed in the analysis below, the inclusion of the term 'research' into the phrase is intentional and signifies a broadening of the concept of innovation.

\subsection{Step 2: analysis of axiological and ontological assumptions per account}

Following our conceptualization of paradigm, in step two, each source is subjected to a critical hermeneutic analysis. The analysis aims to find (implicit) axiological and 
ontological assumptions underlying the account and to establish their social power relationships.

To identify and articulate the paradigm level assumptions, sources are subjected to a hermeneutic in-depth reading that involves:

- Searching for linguistic features of the text, for example, verbs and demonstratives, that function as a marker or trigger of assumptions (Fairclough 2003).

- Reading and interpreting examples in the text of problems and issues that need to be addresses or solutions to be embraced, as these provide (indirect) evidence of presupposed (implicit) changes at the paradigm level (cf. Alvesson and Sandberg 2011; Burns and Carson 2002; Luoto et al. 2017).

- Detecting where the sources deviate in principle and content from the dominant understanding of innovation (cf. Burns and Carson 2002).

Throughout this process, the current dominant innovation paradigm is taken as a counter-point that helps to detect patterns of change and alignment on the paradigm level between RI and the reigning paradigm. To this end, the historical reconstruction by Godin $(2006,2015,2016)$ of innovation in 20th and start of the 21 st centuries as techno-economic innovation is used to represent the dominant innovation paradigm. The currently dominant mode of innovation governance consists in top-down regulation and legal compliance on the one hand and ex-post accountability and liability on the other (Pellizzoni 2004).

One may argue that this depiction of the dominant paradigm of innovation does not take into account recent developments in the field that move beyond the technoeconomic paradigm. New conceptualizations of innovation such as strategic (Sundbo 1995), social (Howaldt et al. 2016) and open innovation (Baldwin and von Hippel 2009; Chesbrough 2006), for instance, have been discussed in the literature as shifting or even replacing the dominant techno-economic paradigm. However, following Godin (2009), and in line with the literature that discusses these conceptualizations, we contend that similar to RI, any of these conceptualizations yet has to become mainstream, and therefore do not truly replace the assumptions of the dominant paradigm. Moreover, for our current purpose of analyzing the paradigm level assumptions of RI, the dominant paradigm is not meant to be a comprehensive description of views held by the current innovation practice. Rather, it functions as a counter-point that enables to identify and articulate the foundational presuppositions held by the RI discourse on innovation. Table 2 provides an overview of the ontological and axiological assumptions of the dominant innovation paradigm we have discerned for this purpose.

Apart from discursive power exercised by the different authors by forwarding their account of RI, further means of influence (social power) that are exerted by the authors to bringing about a paradigm shift or replacement are left out of the analysis. For example, all authors have been involved in shaping policies related to the funding of research and innovation, on national and European levels. Naturally, the EU keys are part of official European Union Research and Innovation (R\&I) policy, whereas Von Schomberg, although he stated that the views of his account are his own and not 'an official position by the European Commission', was working for 
Table 2 Ontological and axiological assumptions behind the dominant techno-economic innovation paradigm [based on Godin (2006, 2009, 2015, 2016) and Pellizzoni (2003)]

\begin{tabular}{|c|c|}
\hline Ontological assumptions & Axiological assumptions \\
\hline $\begin{array}{l}\text { Innovation predominantly is understood as } \\
\text { technological innovation and not, for example, as } \\
\text { social or service innovation }\end{array}$ & $\begin{array}{l}\text { The capitalist worldview held by dominant } \\
\text { techno-economic paradigm does not entail } \\
\text { particular consideration for societal or ethical } \\
\text { values beyond economic value }\end{array}$ \\
\hline $\begin{array}{l}\text { Innovation is being discussed in economic terms, } \\
\text { such as creating prosperity or improving the } \\
\text { economy and not in broader societal or ethical } \\
\text { terms such as ecology or social justice }\end{array}$ & $\begin{array}{l}\text { Innovation generally is regarded as something } \\
\text { positive, inherently good }\end{array}$ \\
\hline $\begin{array}{l}\text { Innovation is guided by the market-forces and only } \\
\text { steered ex-ante via regulation and legislation. } \\
\text { Therefore, it is assumed that innovation is } \\
\text { positioned outside of the political realm. Policy } \\
\text { and regulation are regarded as setting the } \\
\text { normative and legal constraints within which } \\
\text { innovation operates }\end{array}$ & $\begin{array}{l}\text { Innovation is primarily valuated in economic } \\
\text { terms. Therefore, it can be interpreted to be } \\
\text { lacking a substantive perspective on ethics. } \\
\text { However, because innovation is justified in terms } \\
\text { of its economic consequences, procedurally, it } \\
\text { can be interpreted to have a consequentialist } \\
\text { approach to ethics (cf. Hurley 2011) }\end{array}$ \\
\hline $\begin{array}{l}\text { Although under the dominant paradigm science } \\
\text { and research are regarded as important } \\
\text { contributors and sometimes necessary } \\
\text { prerequisites to innovation, they are seen as } \\
\text { distinct concepts in their own right (see, e.g., } \\
\text { Kline and Rosenberg 1986). Therefore, the } \\
\text { assumptions underlying innovation, i.e. that it is } \\
\text { understood in economic terms, do not } \\
\text { necessarily carry over to science or research }\end{array}$ & $\begin{array}{l}\text { The consequentialism implied under the dominant } \\
\text { paradigm has an individualist rather than } \\
\text { collective outlook. In accordance with the } \\
\text { capitalist market theory, agents valuate the } \\
\text { market supply individually (cf. Hurley 2011). } \\
\text { Responsibility for outcomes of the market } \\
\text { process therefore rests by individuals rather than } \\
\text { by a collective body }\end{array}$ \\
\hline \multicolumn{2}{|l|}{$\begin{array}{l}\text { In line with its techno-economic focus, the type of } \\
\text { actors involved in innovation are those } \\
\text { traditionally associated with innovation such as } \\
\text { engineers, entrepreneurs and managers (Sundbo } \\
\text { 1995) and not wider societal stakeholders }\end{array}$} \\
\hline $\begin{array}{l}\text { As opposed to the recent calls for opening up the } \\
\text { innovation process (see, e.g., Baldwin and von } \\
\text { Hippel 2009; Chesbrough et al. 2006), } \\
\text { innovation is considered as shielded off from the } \\
\text { outside world to protect the competitive } \\
\text { advantage gained through it }\end{array}$ & \\
\hline
\end{tabular}

the Directorate General for Research and Innovation of the European Commission when he published his account (Von Schomberg 2013). Likewise, van den Hoven and the authors of the Stilgoe et al.-account, have been working on national and European R\&I policy, and were involved in several national and European dedicated RI projects (see, e.g., Timmermans 2015b). Although these involvements are of relevance to the understanding of what account of RI has made the most impact on the dominant innovation paradigm, analyzing them goes well beyond our current purpose of understanding how the assumptions underlying RI relate to the dominant paradigm. 


\subsection{Step 3: cross-comparison of accounts}

Based on the analysis of the individual accounts, in step 3, the ontological and axiological paradigm level assumptions of the different accounts of RI are cross-compared. This allows to critically reflect on the accounts in terms of their raising barriers and/or enablers to the envisaged paradigm shift. The analysis is to be structured according to inductively emerging thematic categories that come forward in the cross-comparison.

By alternating between steps two and three, the analysis enters the hermeneutic circle, going back and forth between RI as a whole and its individual parts (cf. Schwandt 2007). This way, the analysis corkscrews towards a deeper understanding of the assumptions of RI and its constitutive accounts.

\section{Analysis}

In this section, the research approach is applied to each of the four accounts of RI we identified. The discussion of each account starts by introducing its origin and salience, followed by a brief overview of the account, and the analyses of the ontological and axiological assumptions.

\subsection{European Commission}

This account of responsible research and innovation $(\mathrm{RRI})^{2}$ was developed by the European Commission (EC) as part of their Science With and for Society (SWAFS) policy (European Commission 2017). Building on previous iterations of EU policies (Rodríguez et al. 2013) it was first discussed in detail in a policy leaflet by the former European Commissioner for Research, Innovation and Science Máire GeogheganQuinn (Geoghegan-Quinn 2012), and later elaborated upon in official EC publications (e.g. European Commission 2015, 2017). ${ }^{3}$ It also is recognized as a central source of the EC account on RRI by the RI literature (Burget et al. 2017; Owen et al. 2012; Timmermans 2017) and EU policy documents (see, e.g., European Commission 2014; Strand et al. 2015).

This account of RRI is especially influential in the European Union, where it was adopted as a cross-cutting issue of the most recent framework programme of the EC (European Commission 2011). Apart from inclusion in diverse science and research projects funded by the EC, also dedicated projects were and are being funded by the EC to further develop and promote the uptake of RRI (see, e.g., GREAT Project 2013; RRI Tools Project 2016; New HoRRIzon Project 2017).

\footnotetext{
2 Because the EC and von Schomberg accounts use RRI rather than RI, in the discussion of these accounts the abbreviation RRI will be deployed instead of RI, which is used elsewhere in this article.

3 Documents such as the Rome Declaration on RRI (European Commission 2014) in Europe and the RRI indicators report (Strand et al. 2015) are excluded from the analysis. Although these documents were published and/or commissioned by the EU they reflect 'the views only of the authors' (see, e.g., Strand et al. 2015) and not those of the EC.
} 


\subsubsection{Overview}

The account of the European Commission (EC) starts from the premise that research and innovation (R\&I) needs to 'respond to the needs and ambitions of society, and reflect its values'. This way R\&I is better able to create 'prosperity' and to 'find the right answers to the [grand societal] challenges we face' such as renewable energy and the ageing population. RRI then involves 'that societal actors (researchers, citizens, policymakers, business, third sector organisations, etc.) work together during the whole research and innovation process in order to better align both the process and its outcomes with the values, needs and expectations of society.' (European Commission 2015).

To operationalize this definition, the EC account introduces six keys of RRI. The most important key, which is regarded as RRI's 'main objective', is public engagement and involving stakeholders. Although the other five keys-gender equality, science education, ethics, open access/open science, and governance-have merit on their own, they are predominantly discussed by the EC account as conditions and enablers of public/stakeholder engagement.

The EC account differs notably from the other three accounts discussed below. Whereas the other accounts provide a rather comprehensive alternative perspective on innovation, the 6 keys of the EC account are related in a less coherent manner. In the first place, the different keys such as gender, transparency and science education are categorically different, and therefore necessarily supplement or complement each other. Moreover, some of the keys could be understood to enclose one or more of the others. Gender, for instance, can be regarded to be encompassed by ethics, while engagement could be regarded as part of governance. Nevertheless, due to its major influence on the RI discourse and within EU funded projects, the account has been included as a single account in this analysis. Despite its wide reach and influence on the discourse, and despite the fact that this account was being developed before and in parallel to them, the other accounts of RI discussed in this paper do not contain any references to the EC account.

\subsubsection{Ontological assumptions}

First, the EC account presupposes a broader view on innovation than does the dominant techno-economic paradigm. On the one hand, the account aligns the dominant paradigm by discussing innovation mainly as technological innovation. Only one time it mentions innovation as 'service innovation'. Also, the EC account discusses innovation in economic terms, for example, as producing prosperity, creating jobs, and improving the economy. On the other hand, it entails a broadening of the purpose and related valuation of innovation, to include tackling societal challenges. To this end, the EC account presupposes a new type of input in the innovation process, namely knowledge about societal values, interests and needs, and new types of actors, i.e. societal actors such as citizens and policymakers, which function as a source of knowledge but also are involved in the 'co-construction' of innovation.

Second, a further broadening of the understanding of innovation consists of its inclusion of 'research' and 'science' into the understanding of innovation. Although 
in the dominant paradigm science and research are regarded as important contributors and sometimes necessary prerequisites to innovation (see, e.g., Kline and Rosenberg 1986), they are seen as separate concepts. As Godin (2009) pointed out, this can be understood as a move by policymakers to project characteristics of innovation, such as having a practical application and economic impact, onto science and research. The EC account, for example, discusses research as a means to 'boost' innovation, and science as 'a bedrock' of a 'healthy economy'. By combining these different concepts into one concept, namely R\&I, assumptions of innovation are carried over to (science and) research, and therefore signals a broadening of the dominant paradigm to a new field of application, namely research.

Third, the EC account requires the innovation process to be 'transparent and accessible'. In contrast to the VS and SOM accounts discussed below, who conceive it as an 'opening up' of the innovation process to (societal) stakeholders, transparency initially was conceived in narrow terms of 'open access' of publications and data of 'publicly-funded research'. Although this call for transparency is at odds with the economic perspective of the dominant paradigm (Blok and Lemmens 2015), the caveat of 'publicly-funded' seems to pre-empt this tension. However, in more recent outings, the EC announced that it is "now moving decisively from "Open access" into the broader picture of "Open science"" (European Commission 2015). In a similar vein, elsewhere, the EC recognizes there to be a trend 'towards opening R\&I activities to societal actors and concerns', which is seen as 'an important means of improving the quality and relevance of R\&I for society'(European Commission 2017). Although these two sources reveal a careful development in the position of the EC they do yet imply a departure from their earlier position.

Fourth, although 'governance' is one of the six keys of the EC account, it does not assume a further broadening of the innovation process by also assuming governance to be a part of innovation (as do the SOM and VS accounts discussed below). The purpose of governance in the EC account is to 'develop harmonious models for Responsible Research and Innovation that integrate public engagement, gender equality, science education, open access and ethics'. Rather than as an active part of R\&I itself, it is understood as a meta-level activity aimed at supporting a responsible R\&I. Policymakers, who are portrayed as the ones responsible for governance, are therefore not regarded as R\&I actors.

\subsubsection{Axiological assumptions}

First, similar to the dominant paradigm of innovation, the EC account presupposes a generally positive outlook on innovation. It is being portrayed as a provider of 'solutions to societal problems and opportunities' covering both economic progress and societal challenges. Moreover, although the account recognizes 'possible public value failures of future innovation', this can be 'pre-empt[-ed]' by the implementation of the RRI keys.

Second, also in line with the dominant paradigm, the EC account (implicitly) is based on a consequentialist approach to ethics, i.e. justifying innovation on the basis of its bringing about (net) positive consequences. The account discusses RRI as a means to meet societal challenges, both 'social, economic and ethical' by providing 
(technological) solutions. Rather than just evaluating the consequences of innovation in terms of marketability and economic benefit bounded by legal constraints, as is prevalent under the techno-economic paradigm, the EC account also adds societal and ethical values to the equation. In general, the RRI key 'ethics' is discussed as a means 'to adequately respond to societal challenges', and as a way of ensuring 'high quality results', 'increased societal relevance', and 'acceptability of R\&I outcomes'. So, rather than a 'constraint to R\&I', as is the case under the dominant paradigm, ethics needs to move 'beyond the mandatory legal aspects' and support innovation in producing ethically/societally desirable outcomes.

Third, besides including societal needs and values held by the European citizens in general, the RRI keys also suggest particular values that need to be included in the evaluation. Transparency, for instance, is discussed as a means to 'boost innovation', while gender balance is viewed as a prerequisite to engagement, which in turn is portrayed as a means to create solutions to societal problems and opportunities. By moving beyond economic value as its sole evaluation criterion (albeit still very important), the EC account creates a potentially deviates from the market-economic outlook of the dominant innovation paradigm. The account itself, however, denies this potential tension between the societal and economic role of innovation by discussing societal desirability and ethical acceptability as a (necessary) means to attain economic prosperity.

Fourth, these particular values such as gender and transparency, not only are discussed from a consequentialist perspective but also from a deontological perspective, i.e. functioning as an end in and by themselves rather than as a means to produce desirable consequences. Moving beyond the dominant techno-economic paradigm gender-balance, inclusiveness, and 'respect fundamental rights and the highest ethical standards' are justified within the innovation process irrespective of their contribution to producing desirable and acceptable outcomes.

\subsection{Van den Hoven}

This account of Responsible Innovation was developed by Jeroen van den Hoven based on previous work on Value-Sensitive Design (VSD) (see, e.g. van den Hoven 2007; van den Hoven et al. 2011). VSD is an approach first introduced in the realm of information technology to incorporate normative values into design processes of artefacts (Friedman et al. 2002). Van den Hoven and others pioneered broadening the application of this approach to design-processes in general, eventually resulting in framing it as a novel way of innovating, named Responsible Innovation (RI) (van den Hoven 2013).

This account of RI especially is influential in the Netherlands, where it has been included as an important feature of the Responsible Innovation (MVI) programme of the Dutch Research Council (NWO) (NWO 2016; van den Hoven 2014). In addition, it has been picked up by the RI discourse and EU policy. For example, the SOM and VS accounts of RI discussed below, both refer to van den Hoven's account albeit not as a distinct account of RI. 


\subsubsection{Overview}

Similar to the other accounts of RI, the VDH account's main objective is to produce societally acceptable and desirable innovations. Its point of departure is the profound impact of innovation on society. According to the VDH account, traditional 'ethics and the law' (van den Hoven 2013) do not succeed in fully meeting this objective. For this reason, the VDH account proposes a 'transition in innovative thinking' based on 'modern applied ethics', namely VSD. It entails 'ethical thinking and moral values' at an 'early stage' of the innovation process. This allows 'morally relevant actors' such as innovators and engineers to 'anticipate and pre-empt moral concerns' in innovation processes early on instead of after their introduction into society.

\subsubsection{Ontological assumptions}

First, the VDH account assumes innovation to be broader than the dominant technoeconomical paradigm. Although technology and technological innovation are taken as its point of departure, the account also includes organizational and process innovation. But more importantly, by explicitly targeting the solution of moral problems, it widens the array of problems that innovation seeks to address. As a consequence, the account presupposes a new type of uncertainty that innovation seeks to overcome. Rather than overcoming epistemic uncertainty, the VDH account aims at overcoming normative uncertainty by including knowledge about moral values to be operationalized in the innovation's design. This also implies new sources where this knowledge is to be found, namely the public, citizens, and (societal) stakeholders.

Second, whereas the dominant paradigm holds that innovation is guided by (impersonal) market-forces only to be steered ex-ante via regulation and liability (Pellizzoni 2004), the VDH account holds the assumption that the innovation process is steerable towards societal desirability and acceptability already early on in the innovation process. The so-called Collingridge dilemma (Collingridge 1980) is overcome by this account by introducing moral values as functional requirements into the innovation process that allows directing the innovation process towards societal acceptability and desirability.

Third, the VDH account does not assume that the innovation process should include the governance of the innovation process. In line with the dominant paradigm, innovation interfaces with society through the market, legislation and regulation. Although society is a source of moral values, the traditional actors involved in the innovation process, such as innovators and engineers, are the ones responsible for innovation. Moral values are 'shared by the public', represented by 'parliament' or 'held by stakeholders'. These sources, however, are not considered to be part of the innovation process.

\subsubsection{Axiological assumptions}

First, similar to the dominant innovation paradigm, the VDH account assumes that innovation is a good thing in itself. It is being argued, for instance, that innovation is desired by 'every country every company'. Moreover, because innovation allows to 
'bring moral progress by solving a moral dilemma', it believes there to be a 'moral obligation' or 'duty' to innovate.

Second, the outlook on innovation that is taken by the account is more ambivalent towards it relationship with the free-market economy (tied to the dominant capitalist worldview). On the one hand, the VDH account assumes an alignment between moral value and economic value as creating moral value is viewed as an enabler for creating 'good economic outcomes'. On the other hand, however, the definition of innovation used by the account notably lacks any reference to the market(-ability) or economic aims of innovation. Moreover, RI is understood by the VDH account as a means to remedy the negative externalities of free-market capitalism.

Third, the VDH account explicitly is based on a consequentialist approach to ethics. This entails 'obtain-[ing]_as much as possible_- the relevant knowledge on (i) the consequences of the outcomes of their actions and on (ii) the range of options open to them and (B) to evaluate both outcomes and options effectively in terms of relevant moral values'. Moreover, besides providing this procedural approach to ethics, the account also makes substantive ethical claims. Moving beyond economic values and efficiency associated with the dominant paradigm, the VDH account, suggests including values such as 'wellbeing, justice, equality, privacy, autonomy, safety, security, [and] sustainability'.

\subsection{Von Schomberg}

This account of Responsible Research and Innovation (RRI) was developed by René von Schomberg (VS) and has been presented in various publications (Von Schomberg, 2011, 2012, 2013, 2014). Although at the time of his writing von Schomberg was working for the Directorate General for Research and Innovation of the European Commission, he explicitly states to voice his 'personal version behind RRI'. Nevertheless, the VS account intentionally takes a 'European policy perspective', criticizing, commenting and building on existing European R\&I policies (Von Schomberg 2013). Apart from being a policymaker, von Schomberg also considers himself to be a 'science and technologies studies [STS] specialist' (Von Schomberg 2017). Like the authors of the SOM account discussed below, he, therefore, can be considered part of that community.

Despite the author's affiliation and unlike the other three accounts discussed in this article, the VS account has never been incorporated into national or European (funding) policy of innovation. However, as some striking similarities between VS and EC definitions of RRI occur (see Sects. 4.2.1, 4.4.1), it does seem to have had a profound influence on EC policymaking. Moreover, being among the first accounts of RI to be published, the VS account has been widely cited (see Timmermans 2017) and discussed by the literature on RRI (e.g. Davis and Laas 2014; Wickson and Carew 2014; Zwart et al. 2014), and used by dedicated RRI projects (see, e.g., GREATProject 2013; RRI Tools Project 2016). And, although they do not build on it, in the discussion of their own SOM account, the authors refer to the VS account as well. 


\subsubsection{Overview}

Like the other accounts, the aspiration of the VS account is to render the products and process of R\&I ethically acceptable and societally desirable. It argues that existing R\&I and accompanying governance frameworks do not succeed in realizing this objective because they evaluate the positive benefits of innovation 'primarily in macro-economic terms', and the negative impact 'exclusively [...] on [technical] safety rather than broader societal and ethical aspects'.

To remedy this, von Schomberg proposes the following definition of RRI: 'Responsible Research and Innovation is a transparent, interactive process by which societal actors and innovators become mutually responsive to each other with a view to the (ethical) acceptability, sustainability and societal desirability of the innovation process and its marketable products (in order to allow a proper embedding of scientific and technological advances in our society).' (p. 63)

The VS account intentionally builds on pre-existing approaches and methods that have a similar aspiration as RRI such as Technology Assessment (TA), STS, midstream modulation, ethics, and anticipatory governance. The VS account does this by positioning RRI as an umbrella term that encompasses all these predecessors. Central to the VS account is the democratization of R\&I by engaging stakeholders and involving societal actors throughout the $R \& I$ process.

\subsubsection{Ontological assumptions}

First, in alignment with the dominant techno-economic innovation paradigm, the VS account discusses innovation as 'technological innovation'. Also, the account presupposes an economic perspective on innovation. Notwithstanding its criticism of the dominant paradigm's too narrow focus on economic benefits, the VS account understands the innovation process as resulting in 'marketable products' and increased 'market competitiveness'.

Second, at the same time, the VS account diverges from the dominant paradigm by assuming a wider range of actors, foremost 'societal actors', to be involved. Furthermore, it assumes a new type of knowledge concerning 'societal needs' and 'constructive input in terms of defining societally-desirable products' that these actors provide. This knowledge is required for the innovation process and outcomes to meet RRI's aspiration to become 'ethically acceptable, societal desirable, sustainable'.

Third, in line with the concept of open innovation (Baldwin and von Hippel 2009; Chesbrough et al. 2006), the VS account requires the innovation process to be 'transparent'. As has been suggested by the literature on open innovation (Chesbrough et al. 2006), the call for opening up (science and) innovation is understood to be in clear tension with the dominant innovation paradigm. Open innovation, therefore, is discussed as involving a 'paradigm shift [...] from producer innovation to user and open collaborative innovation' (Baldwin and von Hippel 2009, pp. 24-32).

Fourth, similar to the EC account, the VS account intentionally relates innovation to 'research and innovation' and on a few occasions, also to 'science'. The definition provided by the account, for instance, talks about responsible R\&I and not just innovation. 
Fifth, the VS account goes beyond the boundaries of the dominant paradigm by presupposing democratic deliberation processes to be included in the innovation process. The account, for instance, proposes innovation to involve an 'ongoing public debate' and 'dialogue amongst' all stakeholders and societal actors, and to encompass 'public deliberation'. As such, the governance of R\&I becomes part of the innovation process itself. In contrast, under the dominant paradigm, governance is regarded as an external process that sets (legal) constraints and ex-ante evaluation of innovations when they are marketed (cf. Pellizzoni 2004).

Sixth, as a consequence, (research and) innovation is assumed by the VS account to be steerable 'towards societally-beneficial objectives' and away from 'negative impacts' already 'at a much earlier stage'. The VS account contrasts its ability to steer innovation through public deliberation/involvement with the dominant technoeconomic paradigm, which is assumed to rely solely on the 'steerless' market as a societal evaluator of innovation.

\subsubsection{Axiological assumptions}

First, beyond the positive outlook of the dominant paradigm of innovation the VS account also acknowledges the negatives sides of innovation. It, for example, explicitly distances itself from the dominant view that 'innovation will automatically lead to the creation of jobs and economic growth, thereby tackling societal challenges along the way.' The relationship between innovation and economy of the VS account, therefore, is more ambivalent than is the case under the dominant paradigm. On the one hand, the account aligns to the techno-economic paradigm by implying that creating marketable products is the purpose of innovation. For example, conducting R\&I responsibly is posited as 'a precondition for a product's viability in market competitive economies'. On the other hand, however, the market does not (necessarily) lead to societally desirable and acceptable innovation. The market-economic outlook of the dominant innovation paradigm, therefore, needs to be complemented by deliberative evaluation processes.

Second, similar to the EC and VDH accounts, the VS account is based on a consequentialist approach to justify innovation. Throughout, the outcomes and processes of (R\&)I are evaluated in terms of 'impact', 'consequences' and 'outcomes'. However, in contrast to the 'narrow' focus of the dominant paradigm's consequentialist evaluation on 'economic benefits' and 'technical risks' it also includes societal desirability, ethical acceptability and sustainability as criteria of evaluation. Moreover, the VS account seeks to actively remedy the known limitations of consequentialism under epistemic uncertainty, i.e. its inability to make valuations if consequences are uncertain or unknown (see van de Poel and Royakkers 2011; Grunwald 2014; Nordmann 2014). Including 'active identification of knowledge gaps' throughout the innovation process, for example, helps to raise the awareness about where knowledge is uncertain or lacking. Also, in situations of epistemic uncertainty or ignorance, the inclusion of the precautionary principle provides 'an incentive to open up alternative R\&D trajectories'.

Third, apart from widening the scope of the consequentialist evaluation, the VS account also proposes what societal and ethical values should be included in the 
evaluation. The 'normative targets' or 'anchor points' that define 'the "right" impacts that R\&I should pursue' are to be found in the 'Treaty on the EU'. Also, the 'Grand Challenges' that need to be tackled by RRI are 'reflected in the Treaty'. So, apart from the societal actors, existing EU documentation is assumed to be a source of normative knowledge. Like the VHD and EC accounts, the VS account thus not only includes a procedural ethics but also a substantive ethics.

Fourth, the VS account proposes a collective perspective on ethics instead of 'an ethics focused on the intentions and/or consequences of actions of individuals', which implicitly is held by the dominant innovation paradigm. Under the dominant paradigm, evaluation of benefits by the market is based on the assessment of consequences by individual agents. Instead, the VS account presupposes 'a collective responsibility both for the right impacts and negative consequences, whether these impacts are intentional or not'. So, whereas under the dominant paradigm each individual has his/her own responsibility to evaluate the innovation, the VS account holds that the evaluation should be done collectively, i.e. via a democratic rather than a market-driven process.

\subsection{Stilgoe, Owen and Macnagten}

This account of Responsible Innovation (RI) was conceived by Jack Stilgoe, Richard Owen and Phil Macnagten (SOM account) (Stilgoe et al. 2013). Although it has been forwarded by the authors via different publications (Owen et al. 2013, 2012, 2012), the Research Policy-version discussed here provides the most comprehensive discussion of the authors' ideas. As comes to the fore in their publications, the authors are researchers in Science and Technology Studies (STS) community on which insights (among others) their account is built.

The SOM account has been of great influence on the RI literature and projects, where it is widely cited (Timmermans 2017), and discussed (e.g. Burget et al. 2017; Wickson and Carew 2014; Zwart et al. 2014). Moreover, the SOM account has been officially adopted by the UK Engineering and Physical Sciences Research Council (EPSRC) (EPSRC 2014; Owen 2014), which also (financially) supported the authors' research (Stilgoe et al. 2013).

\subsubsection{Overview}

The SOM account starts from the aspiration to 'include wider moral responsibility to society' into the innovation process. The 'profound impacts' of innovation and the failure of existing innovation (governance) to take societal and ethical aspects into consideration call for a 'democratisation' of science and innovation. To this end, the SOM account proposes a Responsible innovation that is both future-oriented and democratic, defining it as 'taking care of the future through collective stewardship of science and innovation in the present'. Elaborating upon their definition, the account goes on to offer a framework for RI that consists of the four dimensions anticipation, reflection, inclusion and responsiveness (Stilgoe et al. 2013). 


\subsubsection{Ontological assumptions}

First, in alignment with the dominant techno-economic paradigm the SOM account predominantly discusses innovation as technological innovation. The account, for instance, discusses the need for RI to 'interrogate [...] technological options' and to 'open up debates around science and emerging technologies'.

Second, the SOM account presupposes a broadening of the dominant paradigm by including 'science' into the innovation process, to form one 'science and innovation process'. In the definition offered by the SOM account, for instance, RI is understood as 'collective stewardship of science and innovation'. So, similar to the EC account, science is combined with innovation to form one concept, whereas under the dominant paradigm science is distinguished from innovation albeit being regarded as an important contributor to innovation (Kline and Rosenberg 1986).

Third, a further broadening of the dominant innovation paradigm by the SOM account is due to its presupposing a wider range of actors to be involved in the innovation process. In line with the VS and EC accounts discussed above, the SOM account calls for a more inclusive innovation process, 'moving beyond engagement with stakeholders to include members of the wider public'. Furthermore, this involvement ensures that a new type of knowledge regarding the 'social, political and ethical implications' is included in the innovation process.

Fourth, the SOM account assumes a further broadening of the dominant innovation paradigm by arguing for the 'democratisation' of science and innovation governance as part of the innovation process. To this end, the SOM account, for instance, proposes to 'open up [debates about] science and innovation', 'the creation of new spaces of public dialogue' and the 'embedding [of] deliberation into the innovation process'. By requiring the dimensions of RI to be integrated and embedded into the governance of science and innovation, the account presupposes a wider innovation ecosystem that integrates (democratic) governance into the innovation process. Analogous to the VS account, the SOM account explicitly distances itself from the dominant innovation paradigm with regards to the steerability of (science and) innovation beyond the market and legislation. Whereas the dominant paradigm innovation lets the 'future take care of itself', the SOM account 'support[s] the feasibility and desirability of shaping or steering science and innovation'.

Fifth, similar to the VS and EC accounts, the suggested democratization includes a commitment 'to openness and transparency'. As has been pointed out above, based on the literature on open innovation the call for opening up (science and) innovation is understood as a substantial divergence from the dominant innovation paradigm.

\subsubsection{Axiological assumptions}

First, the SOM account criticizes the consequentialist ethics prevalent under the dominant innovation paradigm for 'bolster[ing] the narrow instrumental expectations of innovators' and 'obscur[ing] areas of uncertainty and ignorance about both risks and benefits.' Consequentialist evaluation of innovation is thus being critiqued for being too (technologically) deterministic, and, in line with the VS account, having a too narrow view of risk and uncertainty. To remedy this, the SOM account proposes to 
overcome the epistemic uncertainty of innovation by including 'anticipating and gaining knowledge of possible consequences', 'interogat[ing] the purposes of innovation' into the innovation process and by explicitly recognizing and reflecting on the limits of consequentialism.

Second, a more important alternative to the consequentialism of the dominant techno-economic paradigm is the account's proposal to replace and complement it with care ethics and virtue ethics. ${ }^{4}$ Building on the care ethics approach to responsibility by Adam and Groves (2011) and Groves (2006), the SOM account defines RI as 'taking care of the future [...]'. In this view, justification of innovation based on desirable impact and outcomes is replaced by the non-reciprocal relationship of care for future generations. Likewise, the SOM account builds on Pellizzoni's (2004) understanding of responsiveness as a forward-looking responsibility to build the "capacity to respond to [possible consequences of innovation] even if yet unknown'. Moreover, the SOM account links this capacity to respond to a 'reflexive capacity' both 'among scientists and within institutions'. Rather than a consequentialist ethics, capacity building to deal with societal and normative challenges can be interpreted as a virtue ethics approach to RI. With this approach, innovation is justified based on the (moral) character traits of the actors 5 involved rather than by producing the right outcomes.

Third, apart from virtue and care ethics, the SOM account also has deontological undertones distancing it further from the consequentialist axiology of the dominant innovation paradigm. The account, for example, discusses the possibility to justify innovations based on the 'purposes, motivations', 'commitments and assumptions' behind it. With this, it focusses on intentions and principles, rather than on consequences.

Despite encompassing three ethical theories, the SOM account does not apply ethics into their RI framework. Instead, reflection is understood in socio-political terms targeting purposes, motivations and implications of innovation rather than (moral) values. So, rather than introducing ethical thinking into the innovation process like the $\mathrm{VDH}, \mathrm{EC}$ and VS accounts do, the SOM account proposes a democratization of the broader innovation process.

Fourth, in order to ensure the validity of their version of RI across 'different areas of innovation, and in different cultural contexts', the SOM account is 'reticent to explicitly define the normative ends of RI. As a consequence, the SOM account takes a strictly procedural approach to ethics.

\section{Discussion}

In this section, the implications of the individual accounts of RI are mutually compared to each other and then critically reflected upon in terms of their raising barriers and/or

\footnotetext{
4 It may be argued that care and virtue ethics do not play an important role in the way the SOM account has been taken up in the literature. However, in the primary sources considered here, i.e. the publications, they do. Moreover, as is being argued here, the dimension of responsiveness, which integrates the three other dimensions, can be understood to be representing care/virtue ethics.

5 Whereas virtue ethics traditionally solely was focussed at virtues of individual persons, more recently virtue ethics also got associated with organisations (see, e.g., Alzola 2017; Chun 2005; Moore 2005).
} 
enablers to the envisaged paradigm shift. While iterating between steps two and three of the research approach, overarching thematic categories emerged: seven ontological assumptions and four axiological assumptions (displayed in bold font). Together, these can be understood to signify the dimensions of the transition of the dominant paradigm that is needed to meet RI's ethical and societal aspirations. The first two parts of this section discuss the ontological and axiological assumptions and are structured according to the thematic categories. The third part discusses implications of the assumptions from a general perspective.

\subsection{Ontological assumptions}

First, in terms of what types of innovation are assumed to be part of RI, all four accounts are closely aligned to the dominant techno-economic paradigm. Two of the accounts (EC and VDH) mention other types of innovation such as service or process innovation. Nevertheless, in line with the techno-economic paradigm innovation, foremost innovation is being discussed by all four accounts as technological innovation. On the one hand, alignment with the dominant paradigm may increase the acceptance of the accounts by the innovation community thereby acting as an enabler for the shift. On the other hand, alternative types of innovation such as system or business model innovation, which also may be of relevance to meeting RI's aspiration, are (almost) not considered or appealed to by the accounts.

Second, it turned out that, in line with the dominant paradigm, the various accounts of RI regard innovation as an economic phenomenon aimed at producing marketable goods and profit. Again, this counts as an enabler to the taking up of RI by innovation actors such as businesses. This alignment, however, may also hinder meeting RI's aspirations. It is argued, for example, that attaining an eco-friendly sustainable society may require transcending above the economic framing (Lozano 2008). At the same time, the accounts go beyond the dominant paradigm by presupposing a broadening by adding a societal and/or ethical dimension. These dimensions are considered to be complementary (EC and VDH) or partly replacing (VS and SOM) the dominant paradigm's (narrow) market perspective.

Third, apart from the VDH account, the accounts assume a broadening of the dominant innovation paradigm by including research and/or science into the innovation process. ${ }^{6}$ Under the dominant paradigm, science and research are considered separate concepts from innovation (Kline and Rosenberg 1986). The EC, VS and SOM accounts, however, assume them to be a part of the innovation process itself. For the EC and VS accounts, this broadening (also) is policy driven. It is part of the effort of policymakers to project the characteristics of innovation onto science and research (Godin 2009). This would suggest that rather than innovation, research is the main target of R\&I policy and thereby of R[R]I policy. The broadening by the SOM account ties in with the authors' affiliation with STS, which focuses on science rather

\footnotetext{
6 There has been a longstanding discussion on the status of and relationship between science, research and innovation. Therefore, we acknowledge that opposing positions may be argued for. Nevertheless, considering the policy-laden context of RI adhere to the political argument brought forward by Godin (2009).
} 
than innovation. This means a departure from the dominant paradigm, as it enables STS assumptions about science, for instance, science as a social construction, to be projected onto innovation.

For both accounts, the broadening of their understanding of innovation stems from the community that the authors of the accounts are affiliated with, namely STS and policymaking. This raises the question whether the assumed alterations to the dominant paradigm caused by this broadening are intended to overcome the flaws of the dominant paradigm or just an unintended residue of the authors' original community's assumptions. If the latter is the case, the assumed broadening by the accounts may be superfluous and act as an unnecessary barrier to the overall desired paradigm shift, namely by causing resistance or reluctance within the innovation community to adopt the account. Moreover, an additional explanation may be that the authors, by framing innovation in their original community's terms, seek to raise the relevance of their field in the realm of innovation. In contemporary society, innovation is omnipresent, receiving much attention, esteem and investment (Godin 2016). Besides being part of their effort to influence innovation to become more responsible, framing innovation in new terms may also be understood as part of a strategy by the authors to enter the innovation realm and share in its (financial) benefits.

Fourth, the broadening of the valuation of innovation leads all accounts to broaden the type of knowledge assumed to be included, and except for the VDH account, also the type of actors involved in the innovation process. So, while the VDH account deviates from the dominant paradigm by presupposing a novel type of knowledge, i.e. moral knowledge, it still assumes the actors that provide this knowledge to be external to the innovation process. According to the VDH account, they are only passively involved as sources of moral knowledge. This aligns with the dominant paradigm, which primarily involves stakeholders for economic reasons, even under recent developments such as open innovation (Long and Blok 2018). A further deviation from the dominant innovation paradigm is assumed by the EC, VS and SOM accounts. These accounts not only presuppose the inclusion of new types of knowledge, in this case about societal values, interests and implications, but also the active involvement of societal actors and stakeholders to provide input (VS) or, beyond that, in the 'coconstruction' of innovation (EC and SOM). Moving beyond the dominant paradigm, these accounts of RI thus involve stakeholders for societal rather than (merely) economic reasons. This means that, for instance, members of the public are engaged as citizens and not just in their role as users or consumers.

Both types of broadening assumptions, however, raise important issues regarding their feasibility. For example, knowledge about moral or societal values, which is needed to steer innovation, may be absent or fraught with uncertainty, as epistemic uncertainty coincides with or engenders normative uncertainty (Grunwald 2011). Also, knowledge may be contested and therefore not readily be applicable to the innovation process. And even if it is certain and uncontested, knowledge about moral or societal values may not be readily 'measured', aggregated or operationalized into innovation (see van de Poel (2013) for a theoretical discussion regarding the inclusion of moral values). Likewise, the introduction of new (roles and reasons for inclusion of) actors raises questions about the capacity and motivation of societal actors to be included into the innovation process and, vice versa, of the ability and motivation of innovation 
actors to engage with societal actors. Assuming new types of knowledge and actors to be introduced in the innovation process, therefore, raises further barriers that need to be negotiated for a transition of the dominant paradigm to be tenable.

Fifth, all accounts assume an increase in the level of steerability of innovation towards societal desirability and ethical acceptability relative to the dominant innovation paradigm. Under the dominant paradigm, steering is limited to marketability of innovations within the constraints set by the legal and regulatory framework (Pellizzoni 2004). Again, the different accounts assume different types of deviations from the dominant paradigm. By assuming additional steerability of the innovation process early on by including moral values into the innovation process the VDH account assumes a direct steering of the innovation process within the innovation process itself. Apart from this intervention in the innovation process, the VDH account does not move away from strict steering by the market. Rather, the account assumes there to be alignment between ethical and societal values and marketability. In contrast with the VDH account, the other three accounts (also) assume steering of the innovation process more indirectly by proposing governance and/or democratization of the innovation process. The EC account implicitly assumes additional steerability of the innovation process both top-down via innovation policy and as part of the innovation process via public and stakeholder engagement. In the same vein, the VS and SOM accounts explicitly presuppose steering and shaping of innovation to be feasible and desirable (to remedy the steer-less market) throughout the broadened and democratized innovation process.

The assumption of (increased) steerability raises the issues of both its feasibility and legitimacy. As a radical departure from the dominant paradigm, and considering concerns raised about steerability of innovation by Collingridge (1980), it needs to become clear whether, when, where and how an increase in steerability is practically or in principle possible. To make the argument convincingly to the innovation community, practical evidence supporting this assumption may be required to overcome resistance or reluctance to adopt it. But more importantly, even if steering (early on) is feasible as the accounts assume it to be, steering by innovation actors (even if societal actors are involved) raises the question of legitimacy. On the one hand, the accounts argue that (additional) steering is required because the institutions under the dominant paradigm (market and legislation) are inept at meeting RI's aspiration, leading to the so-called legitimacy vacuum (Pellizzoni 2004). On the other hand, the new institutional arrangements as part of the innovation process may not have the same democratic and judicial legitimacy as do the current institutional arrangements under the dominant paradigm.

Sixth, the assumption of steerability is mirrored by the VS and SOM accounts in their inclusion of governance as part of the innovation process. Under the VDH and EC accounts innovation, governance still remains a separate process. The VS and especially SOM account, however, go well beyond the dominant paradigm by presupposing that (research/science and) innovation governance is part of the innovation process itself. Apart from arousing resistance by the innovation community about drawing the innovation process into the public domain, including governance also raises questions of feasibility and legitimacy. It is, for instance, unclear whether innovation actors have the capacity and are motivated to accommodate this re-allocation of moral labor (Cf. Fisher and Rip 2013) from policymakers and regulators to innovators. 
More importantly, similar to the assumption of steerability, the re-division of moral labor implies that legitimate legal and democratic institutions have to be replaced by new types of institutional arrangements that yet have to prove their legitimacy. It is, for instance, unclear whether the same level of judicial and democratic scrutiny will be warranted when moral responsibilities are shifted towards innovators.

Seventh, related to the increase in steerability and inclusion of governance, the EC, VS and SOM accounts assume that the innovation process should be transparent and/or open. It has been argued that transparency of innovation is at odds with the economic perspective of the dominant paradigm as it goes against the competitive advantage of having exclusive access to an innovation (Blok and Lemmens 2015). The EC account, however, forgoes these potential tensions with the dominant paradigm by limiting its call for transparency to publicly funded research rather than innovation in general. Moving beyond the EC account, the SOM (explicitly) and VS (implicitly through its call for democratic deliberation) accounts require an opening up of the innovation process. While transparency is a necessary condition for an open innovation process (Blok and Lemmens 2015), opening up innovation is much more demanding than transparency. Moreover, as suggested by the literature on open innovation, which resonates deeply with the call for opening up innovation by the VS and SOM accounts, open innovation itself involves a paradigm shift (Baldwin and von Hippel 2009; Chesbrough et al. 2006).

\subsection{Axiological assumptions}

First, all accounts of RI share a generally positive outlook on innovation with the dominant paradigm although they are adding more nuance with regards to the (potential) negative consequences of innovation. The EC and VDH account position innovation as a solution to societal or ethical issues. Possible negative outcomes or dilemmas can be addressed by doing innovation responsibly. The assumptions held by the VS and SOM accounts are in a starker contrast with the dominant paradigm by questioning its one-sided positive outlook on innovation. Nevertheless, all accounts still assume innovation to produce societal benefit and to contribute to tackling societal challenges. This reliance, however, may be unjustified. Optimism about innovation may lead to the fallacy of the 'technology fix', i.e. perceiving possible solutions for ethical and societal issues in narrow (technological) innovation terms (see, e.g., Huesemann and Huesemann 2011; Rosner 2004; Sarewitz and Nelson 2008).

Second, in alignment with the dominant innovation paradigm, all four accounts deploy a consequentialist ethics to justify innovation. They, however, also suggest adapting and supplementing it to compensate for the perceived flaws of the dominant paradigm's way of applying it. Whereas under the dominant paradigm only market benefits and technical risks are taken into consideration, the four accounts, for instance, suggest broadening the consequentialist evaluation. The VDH account adds moral values to the evaluation, while the VS and the EC accounts introduce ethical and societal values. Beyond this, the SOM also calls for recognition and reflection on the weaknesses of consequentialism such as the limits to knowledge, uncertainties and path dependency. 
Most aligned with the dominant paradigm in this respect are the VDH and VS accounts who both also solely deploy a consequentialist ethics. The VS account, however, goes beyond the VDH account. It also presupposes replacing the individualist perspective on ethics, which is prevalent under the dominant paradigm, for a collective responsibility for the impacts of innovation. Such a collective evaluation of innovation would require a further broadening of the paradigm, for instance, by the inclusion of societal actors and governance into the innovation process.

Again, alignment with the dominant paradigm can be seen as an enabler for the uptake of RI by the innovation community. By including a consequentialist approach, however, the accounts of RI are susceptible to the known flaws of consequentialism, such as its ineptness under (epistemic) uncertainty, they set out to remedy. Moreover, by continuing to adhere to an economic perspective on innovation, commercial benefit still may dominate over social and ethical values. The VDH, VS and EC accounts, for instance, all make the argument that having societal or moral value is a precondition for innovation's marketability and economic benefit.

Third, besides a consequentialist ethics to justify innovation, in contrast to the dominant paradigm, the EC and SOM accounts also presuppose using alternative ethical theories. While the EC account mainly uses consequentialist ethics, it also introduces a deontological perspective by valuing gender, inclusiveness and rights as ends in themselves. The most significant departure from the dominant paradigm in this respect is made by the SOM account. Apart from displaying deontological undertones this account also introduces care and a virtue ethics approaches to justifying innovation.

On the one hand, presupposing alternative ethical approaches allows a more comprehensive valuation of innovation. By each stressing different aspects of a situation, the various ethical theories can be understood as complementing each other (van de Poel and Royakkers 2011). So, by invoking alternative theories, the weaknesses of the consequentialist approach are addressed by the accounts. On the other hand, moving away from dominant innovation paradigm's consequentialism, like the other paradigm level divergences, also must be regarded as a barrier to the uptake of RI. Moreover, apart from compensating for the weaknesses of consequentialism, the alternative theories have some known weaknesses of their own. Care ethics, for instance, is known to be vague in the sense that it is unclear what 'care' exactly entails, while virtue ethics fails to provide concrete clues about how to act (van de Poel and Royakkers 2011).

Fourth, the SOM account proposes a procedural ethical approach, leaving open what societal or moral values are to be included in the evaluation of innovation. Apart from transparency, inclusion, and gender, which are part of their RI keys, this is also the case for the EC account. On the one hand, having a procedural approach ensures the versatility of accounts and pre-empts cultural biases. On the other hand, however, the lack of substance and concreteness, at the same time, may prove to be a barrier to the adaptation of RI by the innovation community. To a lesser extent, this also holds for the accounts that do provide ethical substance. The normative anchor points of the EU Treaty suggested by the VS account, for example, still are of a very high level of abstractness and are open to interpretation in practice. 


\subsection{General perspective}

As is pointed out before, the accounts of RI have been developed next to each other and do not build on each other. This is reflected by the ontological and axiological assumptions held by the different accounts. Although there is overlap between their assumptions, there are also notable differences in the levels of alignment/divergence to/from the dominant paradigm. For example, the VDH account suggests a broadening of the dominant paradigm's consequentialist evaluation of innovation by including moral values while the other accounts go further by also including societal values or even adopting alternative ethical theories. Although originally the accounts each were positioned as distinct by their authors, consecutive authors made efforts to unify the concept by drawing out overlapping characteristics (see, e.g., Burget et al. 2017; Lubberink et al. 2017; RRI Tools Project 2016; Wickson and Carew 2014). In the meantime, the concept generally is being treated as if it is unified in contemporary academic and policy debates on RI. This explains why, although it is being acknowledged that RI is still an emerging phenomenon and therefore contested (see, e.g., Owen et al. 2013; Stahl 2013), differences (on a paradigm level) between the accounts have been neglected often.

Not surprisingly, a broadening of the assumptions on an axiological level coincides with a broadening on an ontological level. For instance, a further departure from the dominant paradigm in the valuation and justification of innovation coincides with a broadening in terms of new types of knowledge, actors and inclusion of governance into the innovation process. The level of alignment of an assumption means a better fit of the account within the current innovation paradigm. Overlapping assumptions such as a techno-economic understanding of innovation and a consequentialist justification of innovation act as enablers for the easy uptake of that account by the innovation community. On the other hand, diverging assumptions pose barriers to such an easy adoption and in fact, requires a paradigm shift to become adopted/adoptable by the innovation community. For instance, the inclusion of societal values by the VS and EC accounts amounts to a departure from the dominant paradigm that needs to be overcome. Less drastic changes are likely to meet less resistance or reluctance by the innovation community.

At the same time, more alignment also indicates that accounts assume less novelty (on a fundamental level) in comparison with the current innovation paradigm. Assuming that all four accounts share the overarching aspiration of RI, meeting it, therefore, may be different for the different thematic categories. To give an example, in the ontological category 'transparency', the VDH does not assume a departure from the dominant paradigm, while a more drastic transition is assumed by the EC and VS and especially the SOM accounts. For each category, it may be disputed, however, whether no or a mild transition suffice in meeting the aspiration of RI or a more drastic transition actually is necessary to fully do so.

Moreover, even if a drastic transition would be required to truly meet RI's aspiration it may not be feasible in practice or principle. For example, the level of additional steerability that is required by the various accounts may be ideologically desirable, but its feasibility has to be empirically proven still. And, even if additional steerability is both feasible and necessary, the accounts raise the question of their democratic and 
judicial legitimacy. Especially the VS and SOM accounts of RI assume fundamental changes at the institutional level.

Under the dominant paradigm, the moral labor of steering and evaluating innovation is the responsibility of legislative bodies that have democratic legitimacy and of the juridical system. Despite its engaging of societal actors, a responsible innovation process, however, would still lack the democratic and judicial legitimacy of the traditional institutions. On the one hand, this may only be a practical matter of currently missing mechanisms and frameworks to support the implementation of RI. On the other hand, as a matter of principle, RI may not be able to sustain the proper checks and balances and due diligence that would be required to legitimize RI. For example, it may prove to be impossible to include a representative sample of the public into the innovation processes or to stage an impartial public deliberation about the acceptability of the implications of innovation.

All four accounts of RI are brought forward by authors that are themselves not a member of the innovation paradigm community. Instead, the authors are members of the applied ethics (VDH) and STS (VS and SOM) communities and/or the European policy community (VS and EC). As a consequence, some of the assumptions of the accounts can be traced back to the external communities and the disciplines they come from. For instance, the assumptions of science as part of innovation and the societal/democratic outlook on innovation held by the VS and SOM accounts also are part of the worldview held by the STS community. Although some of these assumptions may be necessary constituents of the RI account they also just may be legacy assumptions that are not really needed to meet RI's aspiration. In that case, these assumptions would pose unnecessary hurdles to the paradigm shift needed to meet RI's aims. Moreover, the fact that the assumed changes of the innovation paradigm are proposed by authors that are external to the innovation community may itself raise a further barrier. Making changes from the inside out and bottom up by innovation actors who are familiar with innovation practice and are recognized by their fellow community members may meet less resistance and be more effective. However, the argument could also be made that being external has the advantage of bringing an unbiased perspective that includes a new set of assumptions that is needed for the transition.

At the same time, shifting the assumptions held by the innovation community towards those of the authors' community may be motivated beyond intrinsic reasons of rendering innovation more societally and ethically desirable. As Godin (2009) points out, the combining of science and research with innovation also is politically motivated. It enabled to increase the managerial and political control over research and innovation. In a similar vein, the (top-down) introduction of their accounts imposing their assumptions via national (VDH, SOM) and European (EC) funding programs can be understood as part of extending the control over research, science and innovation. Moreover, as discussed above (Sect. 7.1), aligning innovation to the assumptions of their external disciplinary community may also be motivated as a strategy to their community entering the innovation realm and sharing the (financial) benefits innovation currently enjoys. 


\section{Conclusion}

This paper investigated the axiological and ontological paradigm level assumptions of four salient RI accounts in comparison to the dominant techno-economic innovation paradigm. The moving away from the dominant paradigm of the different RI accounts depicts the transition needed to meet the overarching aspiration of RI to render the process and outcomes of innovation in an ethically acceptable and societally desirable way. A critical hermeneutic analysis of the accounts led to the emergence of eleven thematic categories of assumptions in which the accounts show alignment and/or divergence from the dominant paradigm. Despite there being some overlap between them, the level of alignment/divergence of the accounts with the dominant paradigm also differed significantly across these categories.

The assumption-level variety encountered between the four accounts also means that, in contrast with the RI discourse that predominantly discusses RI as if it is a single concept, on the paradigm level there are several distinct outlooks. Mirroring this lack of a shared RI paradigm, also the RI community is still fragmented along disciplinary lines of the communities that brought forward their own accounts such as the EC policymakers, STS, and applied ethics.

This raises the questions whether we deal with one single concept of RI and whether one account of RI is preferable? On the one hand, having one conceptualization provides conceptual clarity and uniformity to the discourse and practice, which may increase the chance that RI meets its aspiration. On the other hand, in the end, competition among accounts may make the concept stronger and also allows to vary depending on the particular needs of different types of innovation or contexts, such as fundamental research and business. This, however, would require acknowledging and communicating the (fundamental) differences between the accounts

All four accounts have been brought forward by authors that are external to the innovation community. Acknowledging their position as outsiders would contribute to a better understanding by the RI community of the (expected) resistance by the innovation community to the proposed changes. Also, it is recommended for the RI community to reflect on their relationship with the innovation community and to engage and involve them more actively into RI.

In addition, the assumed feasibility and the legitimacy of the accounts currently still suffer from a lack underpinning. For example, the assumed steerability and judicial and democratic legitimacy of new institutional arrangements are presupposed but lack empirical or rational substantiation. It is, therefore, recommended that the assumptions and claims of RI are substantiated further via reasoned argument and empirical evidence.

Despite the call by Owen et al. (2013) to do so, the RI community still lacks reflection on its own purposes, aims, implications, and assumptions. The analysis and findings of this article can serve as a starting point to support further reflection by the RI community. To that end, the critical hermeneutic approach used here can be extended beyond literary sources to include the paradigm level assumptions underpinning the choices and actions undertaken by the RI and innovation community members in their everyday practices. Moreover, by broadening its critical perspective to include inquiry 
into the means of influence (social power) will enable to reflect on why (reasons) and how (means) the current innovation paradigm is being shifted or replaced.

Acknowledgements The authors would like to thank the anonymous reviewers for their valuable comments and suggestions to improve the quality of the paper.

Open Access This article is distributed under the terms of the Creative Commons Attribution 4.0 International License (http://creativecommons.org/licenses/by/4.0/), which permits unrestricted use, distribution, and reproduction in any medium, provided you give appropriate credit to the original author(s) and the source, provide a link to the Creative Commons license, and indicate if changes were made.

\section{References}

Adam, B., \& Groves, C. (2011). Futures tended: Care and future-oriented responsibility. Bulletin of Science, Technology and Society, 31(1), 17-27.

Alvesson, M., \& Sandberg, J. (2011). Generating research questions through problematization. Academy of Management Review, 36(2), 247-271.

Alzola, M. (2017). Corporate roles and virtues. In A. J. G. Sison, G. R. Beabout, \& I. Ferrero (Eds.), Handbook of virtue ethics in business and management (pp. 47-56). Dordrecht: Springer.

Baldwin, C., \& von Hippel, E. (2009). MIT Sloan School working paper 4764-09.

Blok, V., \& Lemmens, P. (2015). The emerging concept of responsible innovation. Three reasons why it is questionable and calls for a radical transformation of the concept of innovation. In B.-J. Koops, I. Oosterlaken, H. Romijn, T. Swierstra, \& J. van den Hoven (Eds.), Responsible innovation (Vol. 2, pp. 19-35). Cham: Springer.

Burget, M., Bardone, E., \& Pedaste, M. (2017). Definitions and conceptual dimensions of responsible research and innovation: A literature review. Science and Engineering Ethics, 23(1), 1-19.

Burns, T. R. (2012). The sustainability revolution: A societal paradigm shift. Sustainability, 4(12), 1118-1134.

Burns, T., Calvo, D., \& Carson, M. (Eds.). (2009). Paradigms in public policy: Theory and practice of paradigm shifts in the EU. Berlin: Peter Lang.

Burns, T. R., \& Carson, M. (2002). Actors, paradigms, and institutional dynamics: The theory of social rule systems applied to radical reforms. In J. Rogers Hollingsworth, K. H. Müller \& E. J. Hollingsworth (Eds.), Advancing socio-economics: An institutionalist perspective (pp. 109-147). Lanham, Oxford: Rowman \& Littlefield Publishers.

Burrell, G., \& Morgan, G. (1979). Sociological paradigms and organisational analysis: Elements of the sociology of corporate life (reprinted). Farnham: Ashgate.

Chesbrough, H. W. (2006). The era of open innovation. MIT Sloan Management Review, 44(3), 34-41.

Chesbrough, H., Vanhaverbeke, W., \& West, J. (Eds.). (2006). Open innovation: Researching a new paradigm. Oxford: Oxford University Press.

Chun, R. (2005). Ethical character and virtue of organizations: An empirical assessment and strategic implications. Journal of Business Ethics, 57(3), 269-284.

Collingridge, D. (1980). The social control of technology. London: Frances Pinter.

Davis, M., \& Laas, K. (2014). "Broader impacts" or "responsible research and innovation"? A comparison of two criteria for funding research in science and engineering. Science and Engineering Ethics, 20(4), 963-983.

Denscombe, M. (2008). Communities of practice: A research paradigm for the mixed methods approach. Journal of Mixed Methods Research, 2(3), 270-283.

Denzin, N. K., \& Lincoln, Y. S. (2005). The SAGE handbook of qualitative research. Thousand Oaks: SAGE.

EPSRC. (2014). Framework for responsible innovation: Engineering and physical sciences research council. Retrieved September 10, 2014, from http://www.epsrc.ac.uk/research/framework/.

European Commission. (2011). Horizon 2020: he framework programme for research and innovation, Brussels. Brussels. Retrieved from http://ec.europa.eu/research/horizon2020/pdf/proposals/communi cation_from_the_commission_-_horizon_2020_-_the_framework_programme_for_research_and_in novation.pdf. 
European Commission. (2014). Rome Declaration on Responsible Research and Innovation in Europe (Rome Declaration on Responsible Research and Innovation in Europe). Rome: European Commission. Retrieved from http://ec.europa.eu/research/swafs/pdf/rome_declaration_RRI_final_21_Novem ber.pdf.

European Commission. (2015). Horizon 2020 portal [portal]. Retrieved December 7, 2015, from https://ec .europa.eu/programmes/horizon2020/.

European Commission. (2017). Horizon 2020. Work programme 2018-2020. 16. Science with and for society (HORIZON 2020-Work Programme 2016-2017). Brussels: European Commission.

Fagerberg, J., Martin, B. R., \& Andersen, E. S. (Eds.). (2013). Innovation studies: Evolution and future challenges (1st ed.). Oxford: Oxford University Press.

Fairclough, N. (2003). Analysing discourse: Textual analysis for social research. London: Routledge.

Fisher, E., \& Rip, A. (2013). Responsible Innovation: Multi-level dynamics and soft intervention practices. In R. Owen, M. Heintz, \& J. Bessant (Eds.), Responsible innovation: Managing the responsible emergence of science and innovation in society (pp. 165-183). Chichester: Wiley.

Friedman, B., Kahn, P., \& Borning, A. (2002). Value sensitive design: Theory and methods. University of Washington Technical Report, 02-12.

Geels, F. W. (2002). Technological transitions as evolutionary reconfiguration processes: A multi-level perspective and a case-study. Research Policy, 31(8), 1257-1274.

Geels, F. W. (2005). Processes and patterns in transitions and system innovations: Refining the coevolutionary multi-level perspective. Technological Forecasting and Social Change, 72(6), 681-696.

Geoghegan-Quinn, M. (2012). Responsible research and innovation. Europe's ability to respond to societal challenges. European Union. Retrieved from http://ec.europa.eu/research/science-society.

Given, L. M. (2008). The SAGE encyclopedia of qualitative research methods. Los Angeles, CA: SAGE Publications.

Gladwin, T. N., Kennelly, J. J., \& Krause, T.-S. (1995). Shifting paradigms for sustainable development: Implications for management theory and research. The Academy of Management Review, 20(4), 874.

Godin, B. (2006). The linear model of innovation: The historical construction of an analytical framework. Science, Technology and Human Values, 31(6), 639-667.

Godin, B. (2009). National innovation system: The system approach in historical perspective. Science, Technology and Human Values, 34(4), 476-501.

Godin, B. (2015). Innovation contested: The idea of innovation over the centuries (Vol. 98). New York: Routledge.

Godin, B. (2016). Technological innovation: On the origins and development of an inclusive concept. Technology and Culture, 57(3), 527-556.

GREAT-Project. (2013). GREAT. Governance of REsponsible innovATion. Retrieved December 24, 2015, from http://www.great-project.eu/.

Groves, C. (2006). Technological futures and non-reciprocal responsibility. In Cardiff University. April. School of Social sciences futures conference. Tunis, Tunisia. Retrieved from http://www.cf.ac.uk/soc si/futures/conference/papers/groves.pdf.

Grunwald, A. (2011). Responsible innovation: bringing together technology assessment, applied ethics, and STS research. Enterprise and Work Innovation Studies, 7, 9-31.

Grunwald, A. (2014). The hermeneutic side of responsible research and innovation. Journal of Responsible Innovation, 1(3), 274-291.

Guba, E. G., \& Lincoln, Y. S. (1994). Competing paradigms in qualitative research. In N. K. Denzin \& Y. S. Lincoln (Eds.), Handbook of qualitative research (pp. 105-117). London: SAGE.

Habermas, J. (1978). Knowledge and human interests. Berlin: Heinemann Educational.

Habermas, J. (1984). The theory of communicative action (Vol. I). Boston: Beacon.

Habermas, J. (1988). On the logic of the social sciences. Oxford: Wiley.

Habermas, J. (1990). The hermeneutic claim to universality. In G. L. Ormiston \& A. D. Schrift (Eds.), The hermeneutic tradition: From Ast to Ricoeur. Albany, NY: State University of New York Press.

Howaldt, J., Domanski, D., \& Kaletka, C. (2016). Social innovation: Towards a new innovation paradigm. Mackenzie Management Review, 17(6), 20-44.

Huesemann, M., \& Huesemann, J. (2011). Techno-fix: Why technology won't save us or the environment. Gabriola Island: New Society Publishers.

Hurley, P. (2011). Beyond consequentialism. Oxford: Oxford University Press.

Klaassen, P., Rijnen, M., Vermeulen, S., Broerse, J., \& Kupper, F. (2014). Policy brief on the state of the art on RRI and a working definition of RRI (D1.1) (Deliverable No. D1.1). Amsterdam: Athena Institute. 
Retrieved from http://www.rri-tools.eu/documents/10184/107098/RRITools_D1.1-RRIPolicyBrief.p df/c246dc97-802f-4fe7-a230-2501330ba29b.

Kline, S. J., \& Rosenberg, N. (1986). An overview of innovation. The Positive Sum Strategy: Harnessing Technology for Economic Growth, 14, 640.

Kuhn, T. S. (1962). The structure of scientific revolutions. Chicago: University of Chicago Press.

Long, T. B., \& Blok, V. (2018). Integrating the management of socio-ethical factors into industry innovation: Towards a concept of Open Innovation 2.0. International Food and Agribusiness Management Review, 21(4), 463-486.

Lozano, R. (2008). Envisioning sustainability three-dimensionally. Journal of Cleaner Production, 16(17), 1838-1846.

Lubberink, R., Blok, V., van Ophem, J., \& Omta, O. (2017). Lessons for responsible innovation in the business context: A systematic literature review of responsible, social and sustainable innovation practices. Sustainability, 9(5), 721.

Luoto, S., Brax, S. A., \& Kohtamäki, M. (2017). Critical meta-analysis of servitization research: Constructing a model-narrative to reveal paradigmatic assumptions. Industrial Marketing Management, 60, 89-100.

Mason, P. (2012). Responsible Innovation Framework for commercialisation of research findings. For use in synthetic biology feasibility studies competition 2012: Advancing the Industrial Application of Synthetic Biology. Technology Strategy Board.

Moore, G. (2005). Corporate character: Modern virtue ethics and the virtuous corporation. Business Ethics Quarterly, 15(4), 659-685.

Morgan, D. L. (2007). Paradigms lost and pragmatism regained: methodological implications of combining qualitative and quantitative methods. Journal of Mixed Methods Research, 1(1), 48-76.

New HoRRIzon. (2017). NewHoRRIzon project: Promote the acceptance of RRI in Horizon 2020 and beyond. Retrieved December 18, 2017, from https://newhorrizon.eu/.

Nordmann, A. (2014). Responsible innovation, the art and craft of anticipation. Journal of Responsible Innovation, 1(1), 87-98.

NWO. (2016). NWO-MVI (Maatschappelijk verantwoord innoveren). Retrieved February 20, 2016, from www.nwo.nl/onderzoek-en-resultaten/programmas/maatschappelijk+verantwoord+innoveren.

Owen, R. (2014). The UK Engineering and Physical Sciences Research Council's commitment to a framework for responsible innovation. Journal of Responsible Innovation, 1(1), 113-117.

Owen, R., Macnaghten, P., \& Stilgoe, J. (2012). Responsible research and innovation: From science in society to science for society, with society. Science and Public Policy, 39(6), 751-760.

Owen, R., Stilgoe, J., Macnaghten, P., Gorman, M., Fisher, E., \& Guston, D. H. (2013). A framework for responsible innovation. In R. Owen, M. Heintz, \& J. Bessant (Eds.), Responsible innovation: Managing the responsible emergence of science and innovation in society (pp. 27-50). Chichester: Wiley.

Pellizzoni, L. (2004). Responsibility and environmental governance. Environmental Politics, 13(3), $541-565$.

Ratcliffe, J. W. (1983). Notions of validity in qualitative research methodology. Knowledge, 5(2), 147-167.

Ricoeur, P. (1981). Hermeneutics and the critique of ideology. In J. B. Thompson (Ed.), Hermeneutics and the human sciences: Essays on language, action and interpretation (Vol. 64, pp. 23-60). Cambridge, UK: Cambridge University Press.

Ricoeur, P., \& Thompson, J. B. (1981). Hermeneutics and the human sciences: Essays on language, action and interpretation. Cambridge: Cambridge University Press.

Ritchie, J., \& Lewis, J. (Eds.). (2003). Qualitative research practice: a guide for social science students and researchers. Thousand Oaks, CA: Sage Publications.

Rodríguez, H., Fisher, E., \& Schuurbiers, D. (2013). Integrating science and society in European Framework Programmes: Trends in project-level solicitations. Research Policy, 42(5), 1126-1137.

Rosner, L. (2004). The technological fix: How people use technology to create and solve problems. New York: Psychology Press.

RRI Tools Project. (2016). RRI tools. Retrieved November 14, 2014, from http://www.rri-tools.eu/.

Sarewitz, D., \& Nelson, R. (2008). Three rules for technological fixes. Nature, 456(7224), 871-872.

Schwandt, T. A. (2007). The Sage dictionary of qualitative inquiry (3rd ed.). Thousand Oaks, London, New Delhi: Sage Publications.

Stahl, B. C. (2013). Responsible research and innovation: The role of privacy in an emerging framework. Science and Public Policy, 40(6), 708-716. 
Stahl, B. C., Eden, G., \& Jirotka, M. (2013). Responsible research and innovation in information and communication technology, identifying and engaging with the ethical implications of ICTs. In R. Owen, M. Heintz, \& J. Bessant (Eds.), Responsible innovation: Managing the responsible emergence of science and innovation in society (pp. 199-218). Chichester: Wiley.

Stead, W. E., \& Garner Stead, J. (1994). Can humankind change the economic myth? Paradigm shifts necessary for ecologically sustainable business. Journal of Organizational Change Management, 7(4), $15-31$.

Stilgoe, J., Owen, R., \& Macnaghten, P. (2013). Developing a framework for responsible innovation. Research Policy, 42(9), 1568-1580.

Strand, R., Spaapen, J., Bauer, M. W., Hogan, E., Revuelta, G., Stagl, S., et al. (2015). Indicators for promoting and monitoring responsible research and innovation. Report from the expert group on policy indicators for responsible research and innovation. Luxembourg: European Commission. Retrieved from https://ec.europa.eu/research/swafs/pdf/pub_rri/rri_indicators_final_version.pdf.

Sundbo, J. (1995). Three paradigms in innovation theory. Science and Public Policy, 22(6), 399-410.

Surel, Y. (2000). The role of cognitive and normative frames in policy-making. Journal of European Public Policy, 7(4), 495-512.

Sutcliffe, H. (2011). A report on responsible research \& innovation. Retrieved from http://www.matterfor all.org/pdf/RRI-Report2.pdf.

Timmermans, J. F. C. (2015a). Annual report on RRI 2014: Landscape of RRI discourse (deliverable no. D 6.4-b). FP-7 GREAT Project.

Timmermans, J. F. C. (2015b). Annual report on RRI 2015: Landscape of RRI discourse (deliverable no. D 6.4-c). FP-7 GREAT Project.

Timmermans, J. F. C. (2017). Mapping the RRI Landscape: An overview of Organisations, projects, persons, areas and topics. In L. Asveld, M. E. C. van Dam-Mieras, T. Swierstra, S. A. C. M. Lavrijssen, C. A. Linse, \& M. J. Van Den Hoven (Eds.), Responsible innovation 3: A European agenda? Dordrecht: Springer.

van de Poel, I. (2013). Translating Values into Design Requirements. In D. P. Michelfelder, N. McCarthy, \& D. E. Goldberg (Eds.), Philosophy and engineering: Reflections on practice, principles and process (Vol. 15, pp. 253-266). Dordrecht: Springer.

van de Poel, I., \& Royakkers, L. M. M. (2011). Ethics, technology, and engineering: An introduction. Malden, MA: Wiley.

van den Hoven, J. (2007). ICT and value sensitive design. In P. Goujon, S. Lavelle, P. Duquenoy, K. Kimppa, \& V. Laurent (Eds.), The information society: Innovation, legitimacy, ethics and democracy in honor of Professor Jacques Berleur s.j (pp. 67-72). New York: Springer.

van den Hoven, M. J. (2013). Value sensitive design and responsible innovation. In R. Owen, M. Heintz, \& J. Bessant (Eds.), Responsible innovation: Managing the responsible emergence of science and innovation in society (pp. 75-84). Chichester: Wiley.

van den Hoven, M. J. (2014). Responsible innovation: A new look at technology and ethics. In M. J. van den Hoven, N. Doorn, T. Swierstra, B.-J. Koops, \& H. Romijn (Eds.), Responsible innovation 1 (pp. 3-13). Netherlands: Springer.

van den Hoven, M. J., Lokhorst, G. J., \& van de Poel, I. (2011). Engineering and the problem of moral overload. Science and Engineering Ethics, 18(1), 143-155.

van der Burg, S. (2014). On the hermeneutic need for future anticipation. Journal of Responsible Innovation, 1(1), 99-102.

Von Schomberg, R. (Ed.). (2011). Towards responsible research and innovation in the information and communication technologies and security technologies fields. Brussels: European Commission.

Von Schomberg, R. (2012). Prospects for technology assessment in a framework of responsible research and innovation. In M. Dusseldorp \& R. Beecroft (Eds.), Technikfolgen abschätzen lehren (pp. 39-61). Heidelberg: Berlin.

Von Schomberg, R. (2013). A vision of responsible research and innovation. In R. Owen, M. Heintz, \& J. Bessant (Eds.), Responsible innovation: Managing the responsible emergence of science and innovation in society (pp. 51-74). Chichester: Wiley.

Von Schomberg, R. (2014). The quest for the 'right' impacts of science and technology: A framework for responsible research and innovation. In M. J. van den Hoven, N. Doorn, T. Swierstra, B. J. Koops \& H. Romijn (Eds.), Responsible innovation 1: Innovative solutions for global issues (pp. 33-50). Dordrecht, New York: Springer. 
Von Schomberg, R. (2017). René von Schomberg. Retrieved December 22, 2017, from https://renevonsch omberg.wordpress.com/.

Wall, J., Stahl, B. C., \& Salam, A. F. (2015). Critical discourse analysis as a review methodology: An empirical example. Communications of the Association for Information Systems, 37(11), 257-285.

Wickson, F., \& Carew, A. L. (2014). Quality criteria and indicators for responsible research and innovation: Learning from transdisciplinarity. Journal of Responsible Innovation, 1(3), 254-273.

Zagonari, F. (2016). Four sustainability paradigms for environmental management: A methodological analysis and an empirical study based on 30 Italian industries. Sustainability, 8(6), 504.

Zwart, H., Landeweerd, L., \& Van Rooij, A. (2014). Adapt or perish? Assessing the recent shift in the European research funding arena from 'ELSA'to 'RRI'. Life Sciences, Society and Policy, 10(1), 1-19. 